\title{
BMJ Open Polypharmacy among patients with diabetes: a cross-sectional retrospective study in a tertiary hospital in Saudi Arabia
}

\author{
Monira Alwhaibi, ${ }^{1,2}$ Bander Balkhi, ${ }^{1,2}$ Tariq M Alhawassi, ${ }^{1,2,3}$ Hadeel Alkofide, ${ }^{1}$ \\ Nouf Alduhaim, ${ }^{1}$ Rawan Alabdulali, ${ }^{1}$ Hadeel Drweesh, ${ }^{1}$ Usha Sambamoorthi ${ }^{4}$
}

To cite: Alwhaibi M, Balkhi B, Alhawassi TM, et al. Polypharmacy among patients with diabetes: a cross-sectional retrospective study in a tertiary hospital in Saudi Arabia. BMJ Open 2018;8:e20852. doi:10.1136/ bmjopen-2017-020852

- Prepublication history and additional material for this paper are available online. To view these files, please visit the journal online (http://dx.doi. org/10.1136/bmjopen-2017020852).

Received 29 November 2017 Revised 6 April 2018 Accepted 3 May 2018

Check for updates

${ }^{1}$ Department of Clinical Pharmacy, College of Pharmacy, King Saud University, Riyadh, Saudi Arabia

${ }^{2}$ Medication Safety Research Chair, College of Pharmacy, King Saud University, Riyadh, Saudi Arabia

${ }^{3}$ Pharmacy Service, King Saud University Medical City, Riyadh, Saudi Arabia

${ }^{4}$ Department of Pharmaceutical Systems and Policy, School of Pharmacy, West Virginia University, Morgantown, West Virginia, USA

Correspondence to

Dr Monira Alwhaibi;

malwhaibi@ksu.edu.sa
Abstract Patients with diabetes are at high risk for polypharmacy (ie, use of multiple medications) for treatment of diabetes, associated comorbidities and other coexisting conditions. This study aims to estimate the prevalence of polypharmacy and factors associated with polypharmacy among adult patients with diabetes.

Methods A cross-sectional retrospective observational study of adults with diabetes, who visited the outpatient clinic of a tertiary teaching hospital in Saudi Arabia, was conducted. Data were extracted from the Electronic Health Record database for a period of 12 months (JanuaryDecember 2016). Polypharmacy was defined as the cumulative use of five or more medications. Polypharmacy among adults with diabetes was measured by calculating the average number of medications prescribed per patient. A multivariable logistic regression model was used to examine the factors associated with polypharmacy. Results A total of 8932 adults with diabetes were included in this study. Of these, nearly $78 \%$ had polypharmacy which was more likely among women as compared with men and more likely among older adults (age $\geq 60$ years) as compared with the adults. Also, polypharmacy was two times as likely among patients with coexisting cardiovascular conditions (adjusted OR $(\mathrm{AOR})=2.89 ; 95 \% \mathrm{Cl} 2.54$ to 3.29 ), respiratory disease (AOR=2.42; 95\% Cl 1.92 to 3.03) and mental health conditions (AOR=2.19; 95\% $\mathrm{Cl} 1.74$ to 2.76 ), and three times as likely among patients with coexisting musculoskeletal disease (AOR=3.16; $95 \% \mathrm{Cl} 2.31$ to 4.30 ) as compared with those without these coexisting chronic conditions categories.

Conclusions Polypharmacy is common among patients with diabetes, with an even higher rate in older adults patients. Healthcare providers can help in detecting polypharmacy and in providing recommendations for simplifying medication regimens and minimising medications to enhance the outcome of diabetes care.

\section{INTRODUCTION}

Diabetes is a highly prevalent chronic condition among adults in Saudi Arabia; between $21 \%$ and $24 \%$ of adults are estimated to have diabetes. ${ }^{12}$ It is projected that $27 \%$ of adults in Saudi Arabia will have diabetes by 2035 . $^{3}$ Diabetes is 1 of the top 10 causes of morbidity
Strengths and limitations of this study

- This study has provided a real insight into the current prevalence and predictors of polypharmacy among patients with diabetes in Saudi Arabia including a large study population of patients with diabetes.

- Around 9000 patients were included in this study which allowed us to identify the prevalence of polypharmacy among a subgroup of patients.

- This study has not controlled for the severity of diabetes using the Diabetes Complications Severity Index which may affect the rate of polypharmacy.

- This study used a 12-month period to measure multiple medications use which is not concurrent use and may have resulted in a very high rate of multiple medications uses.

- It has to be noticed that not all polypharmacy is harmful; however, future studies to assess inappropriate medications associated with polypharmacy is warranted.

and mortality worldwide. ${ }^{4}$ Patients with diabetes often have coexisting chronic health conditions such as hypertension, dyslipidaemia, coronary artery disease, depression and chronic kidney disease, which requires the use of multiple medications to treat those coexisting chronic conditions. ${ }^{5}$ All of this put patients with diabetes at high risk of polypharmacy, ${ }^{67}$ with an estimated prevalence of $57 \%-84 \%$ of patients with diabetes using five or more medications. ${ }^{8}$ A study among adults with diabetes in the USA documented that the $54 \%$ of adults with diabetes have polypharmacy. ${ }^{9}$ A multicentre cross-sectional survey conducted in Italy reported that $57 \%$ of patients with diabetes use five or more medications. ${ }^{10}$ In addition, polypharmacy was reported among $84 \%$ older adults patients with diabetes. ${ }^{8}$ In Saudi Arabia, a cross-sectional study among 766 adults who visited outpatient's clinic at a tertiary care centre, 
reported that the prevalence of polypharmacy among patients with diabetes was $71 \% .^{11}$

An examination of polypharmacy among patients with diabetes is important because polypharmacy increases the probability of the adverse drug events, ${ }^{12}{ }^{13}$ drug-drug interactions,${ }^{14}$ duplication of therapy,${ }^{15}$ decreases compliance to antidiabetic medications ${ }^{16}$ and leads to suboptimal glycaemic control. ${ }^{17}$ The presence of polypharmacy is also associated with prescribing cascade, in which adverse drug events are misinterpreted as new medical conditions which can result in the prescription of new medications to treat those conditions. ${ }^{18}$ Polypharmacy has other negative health consequences such as increased risk of hospitalisation and medication error, ${ }^{19}{ }^{20}$ higher risk of fall, ${ }^{21}$ poor functional status, ${ }^{22}$ poor quality of life and high healthcare cost. ${ }^{23}$ Polypharmacy among patients with diabetes is often associated with many factors. These include age,${ }^{11}$ sex,${ }^{10}$ coexisting conditions,${ }^{10}$ rurality ${ }^{11}{ }^{25}$ diabetes complications ${ }^{10}$ and aggressive diabetes treatment. ${ }^{26} 27$

To date, limited studies have examined the prevalence of polypharmacy among adults with diabetes living in Saudi Arabia on a large scale, and assessed the specific factors that put patients at risk of polypharmacy. Identifying the prevalence and the subgroup of patients at high risk of polypharmacy will facilitate pharmacovigilance efforts in clinical practice settings. Therefore, the primary objective of this observational study is to examine the prevalence of polypharmacy among adults with diabetes in Saudi Arabia and to identify the factors that are associated with polypharmacy, specifically the association between coexisting chronic conditions and polypharmacy.

\section{METHODS}

\section{Study design}

A cross-sectional retrospective observational study was conducted in a tertiary teaching hospital in Saudi Arabia. This hospital is one of the largest tertiary teaching hospitals in Riyadh, Saudi Arabia, with a 1200-bed facility and all general and subspecialty medical services. The hospital provides primary, secondary and tertiary care services. The patient population is composed predominantly of local citizens as well as residents, from Northern region in Riyadh; the hospital also serves the entire country as a referral centre.

\section{Data source and data extraction}

This study used data retrieved from the Electronic Health Record (EHR) database for the period from 1 January 2016 to 30 December 2016. Strict confidentiality of the data was maintained throughout the research process. The data from EHR were derived from demographics file, clinical diagnosis file and prescription drug file. The demographics file contained information about the patients' date of birth, gender, marital status, nationality and encounter type. The clinical diagnosis file provided information about the clinical diagnosis from inpatient and outpatient visits. Physicians reported clinical diagnosis using the International Classifications of Diseases, ninth edition, Clinical Modification (ICD-9-CM) codes, ICD-10th edition, CM codes or the Systematised Nomenclature of Medicine diagnosis codes. The prescription drug file contained information about the medications used. The demographics, clinical diagnosis and prescription drug files were merged into one file using the encrypted patient medical record number. The completeness and the validity of the data from EHR in this tertiary teaching hospital in Saudi Arabia has not been studied before; however, the researchers of this study examined the completeness of this data and found that $91.0 \%$ of the patients had a complete data (ie, have information on the age, gender, marital status, nationality, encounter type and clinical diagnosis) and $85.0 \%$ of the patients had complete medication-related information.

\section{Study population}

The study population comprised all adult patients with diabetes (type 1 and type 2 ) (age $\geq 18$ year) ( $n=8932$ ) who received their treatment at the outpatient's setting in the tertiary teaching hospital during a 1-year period. No exclusion criteria were applied to the study population.

\section{Patient and public involvement}

Patients and public were not involved in the design or conduct of this study.

\section{Measures}

\section{Dependent variable}

In our study, the dependent variable was 'polypharmacy'. There are different approaches in the literature to measure polypharmacy such as simultaneous, cumulative and continuous. Also, there is no consensus on the thresholds regarding the number of medications above which we consider the existence of polypharmacy. ${ }^{28}$ In the current study, we defined polypharmacy as the cumulative use of five or more medications during a 1-year period, this threshold has been used more than others. ${ }^{25} 28{ }^{29}$ Using this definition, the prevalence of polypharmacy among adults was measured by the sum of unique therapeutic medication classes administered over a 12-month period. There is no consensus on the medications that should be included in the measurements of the polypharmacy. Also, all the prescription and the non-prescription/over-thecounter (OTC) medications categories were included in our definition of polypharmacy.

\section{Independent variables}

Independent variables included were age groups in years (18-29, 30-39, 40-49, 50-59, 60-69, 70-79, >80), gender, nationality (Saudi, non-Saudi), marital status (married, unmarried) and documented chronic conditions which were classified into five categories (cardiovascular, chronic kidney disease, musculoskeletal, respiratory or mental health conditions) (online supplementary appendix 1). Cardiovascular conditions composed of hypertension, ischaemic heart disease, vascular heart disease, stroke, 
heart failure and dyslipidaemia. Musculoskeletal conditions composed of osteoarthritis and osteoporosis; respiratory conditions include asthma and chronic obstructive pulmonary disease (COPD). Mental health conditions include dementia, depression, anxiety and schizophrenia. These conditions have been selected because they are highly prevalent among patients with diabetes and some of them were associated with polypharmacy. ${ }^{530}$

\section{Statistical analysis}

Frequency and percentage were used to describe the categorical variables (age, sex, marital status, nationality, coexisting chronic conditions and polypharmacy). Mean and SD were used to describe continuous variables. $\chi^{2}$ tests were used to examine the factors associated with polypharmacy. A multivariable logistic regression was used to examine the factors associated with polypharmacy (ie, use of $\geq 5$ medications) after adjusting for age, sex, marital status, nationality and coexisting chronic conditions. All statistical analyses were carried out using the SAS V.9.2.

\section{RESULTS}

A total of 8932 adult patients were identified during the 12 -month period. The majority were Saudi $(89.4 \%)$, female $(62.2 \%)$ and $43.3 \%$ of the study population were older adults (age $\geq 60$ years), the mean age of the study population was 57 years old. About half of the subjects $(54.1 \%)$ had two or more diagnosed coexisting chronic health conditions. Hypertension, dyslipidaemia, asthma, osteoarthritis and anxiety were among the most common chronic conditions in our study population. Characteristics of the study population are presented in table 1 .

\section{Polypharmacy among patients with diabetes}

Overall, $77.9 \%$ of adults with diabetes have used (cumulative) five or more medications. Also, when we identified the rate of hyperpolypharmacy (ie, taking 10 or more medications), we found that $17.2 \%$ of adults have a hyperpolypharmacy. The most commonly used medications in our study population were antidiabetic medications $(81.4 \%)$, followed by non-steroidal anti-inflammatory drugs (NSAIDs) $(72.4 \%)$ and antihyperlipidaemic agents $(68.8 \%)$ (table 2$)$.

The study population characteristics by polypharmacy status are summarised in table 1. This study found a significantly higher percentage of polypharmacy among older adults as compared with patients with age between 18 and 29 years $(84.8 \%$ vs $37.4 \%, \mathrm{p}<0.001)$. Women with diabetes had a significantly higher percentage of polypharmacy as compared with men $(81.7 \%$ vs $71.6 \%$, $\mathrm{p}<0.001$ ). Moreover, polypharmacy was significantly higher among patients with diabetes with two or more coexisting comorbid conditions versus those with no coexisting chronic conditions ( $89.6 \%$ vs $48.6 \%$, $\mathrm{p}<0.001)$. Looking at comorbid conditions closely, polypharmacy was significantly higher among patients with cardiovascular disease $(83.4 \%, \mathrm{p}<0.001)$, chronic kidney disease
(95.2\%, $\mathrm{p}<0.001)$, musculoskeletal (93.6\%, $\mathrm{p}<0.001)$, respiratory $(89.0 \%, \mathrm{p}<0.001)$ and mental health conditions $(85.4 \%, \mathrm{p}<0.001)$ as compared with those without those coexisting chronic conditions.

\section{Logistic regression: factors associated with polypharmacy}

The adjusted ORs (AORs) and 95\% CIs from multivariable logistic regression on polypharmacy are displayed in table 3. Several factors were identified: age, gender and coexisting chronic conditions. Polypharmacy was more likely among older adults as compared with younger adults. Women were more likely to have polypharmacy compared with men (AOR=1.60; 95\% CI 1.43 to 1.79). Cardiovascular diseases, mental conditions, respiratory and musculoskeletal diseases were all significantly associated with polypharmacy. For example, adults with diabetes and musculoskeletal disease were three times more likely to have polypharmacy (AOR $=3.16 ; 95 \%$ CI 2.31 to 4.30$)$ as compared with adults with diabetes and without musculoskeletal conditions.

\section{DISCUSSION}

Our study was set out to examine the prevalence of polypharmacy among adults with diabetes in Saudi Arabia. In this large sample of subjects with diabetes, the rate of polypharmacy was high, as nearly four out of five adults with diabetes were prescribed five or more medications. Similar rates were reported in the literature among patients with diabetes $54 \%-84 \%,{ }^{8-10}$ however, to our knowledge, no study has attempted to measure the rate of polypharmacy among all age groups of adults with diabetes, which is a major contribution of our study. A higher rate of polypharmacy among older individuals (age 60 and above) as compared with all age groups was also observed in this study. Studies among adults in the general population have reported that older adults (defined as age $\geq 60$ or age $\geq 65$ years) have a higher risk of polypharmacy use as compared with adults. ${ }^{31} 32$ One possible reason for the high rate of polypharmacy among this population is the coexistence of other chronic conditions.

Furthermore, a noteworthy finding of the current study is the high prevalence of chronic conditions and the higher rate of polypharmacy among diabetic individuals with coexisting chronic conditions. Previous studies have shown that $90 \%$ of patients with diabetes had at least one coexisting chronic condition, ${ }^{5}$ our study found that $86 \%$ of patients with diabetes had at least one coexisting chronic condition. It is plausible that the high rate of polypharmacy in this study is potentially associated with the number of comorbidities among the study population. The findings of this study support that patients with diabetes with multiple chronic conditions were at higher risk of polypharmacy. ${ }^{53}$ Although there is a well-documented literature on the relationship between the higher number of coexisting conditions and polypharmacy, ${ }^{5} 1034$ our study extended the literature by analysing the association between the type of chronic conditions 


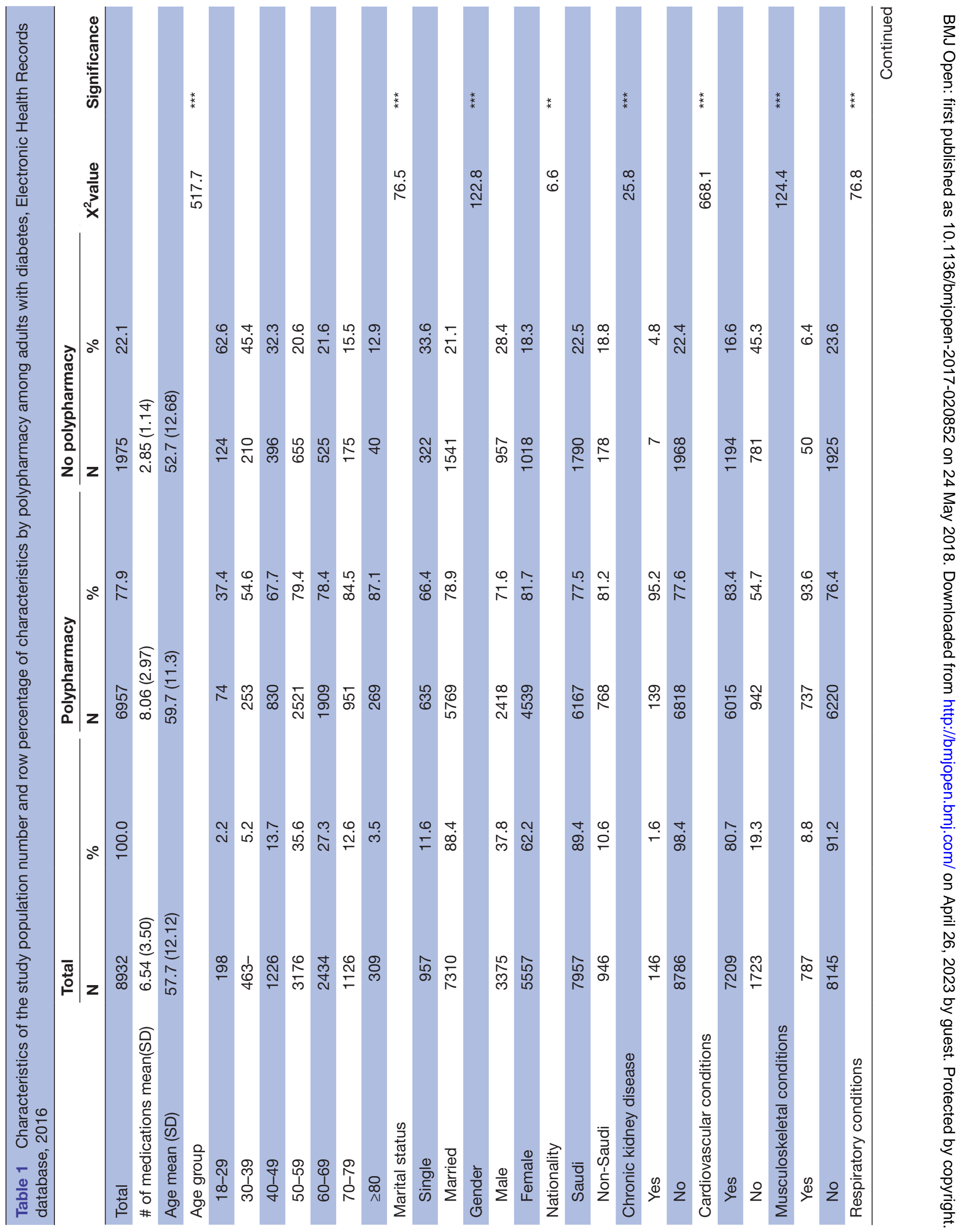




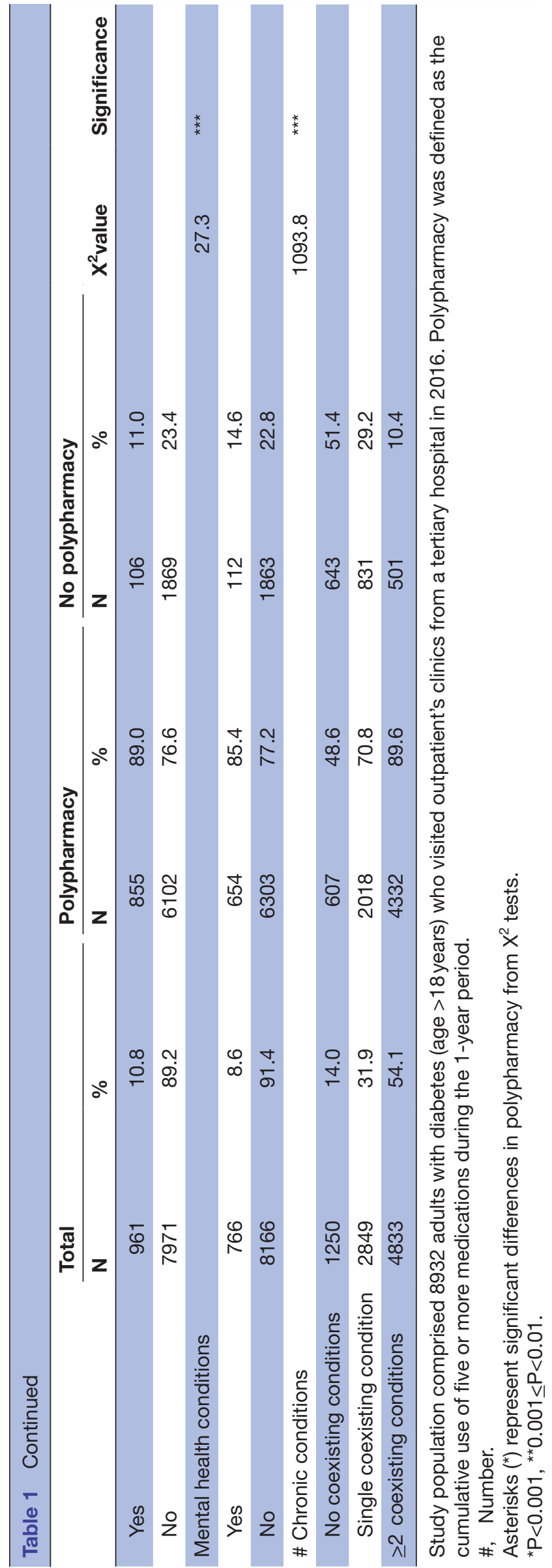

Table 2 Most prevalent therapeutic classes among the study population $(n=8932)$

\begin{tabular}{lcl}
\hline Medication therapy class & N & $\%$ \\
\hline Oral antidiabetic agent & 7270 & 81.4 \\
\hline Non-steroidal anti-inflammatory drugs & 6467 & 72.4 \\
\hline Antihyperlipidaemic agents & 6144 & 68.8 \\
\hline Proton pump inhibitor & 2540 & 28.4 \\
\hline ACE inhibitor & 2321 & 25.9 \\
\hline Injectable antidiabetic agent & 2253 & 25.2 \\
\hline Calcium channel blocker & 2162 & 24.2 \\
\hline Corticosteroid, local & 1892 & 21.1 \\
\hline Diuretic & 1934 & 21.6 \\
\hline Beta-adrenergic blocker, beta-1 & 1806 & 20.2 \\
selective & & \\
\hline Angiotensin II receptor blocker & 1796 & 20.1 \\
\hline Thyroid analogue & 1355 & 15.1 \\
\hline Histamine H2 blocker & 822 & 9.2 \\
\hline Anticoagulants & 706 & 7.9 \\
\hline Corticosteroid, systemic & 600 & 6.7 \\
\hline Antiplatelet & 357 & 4.0 \\
\hline
\end{tabular}

and polypharmacy. We observed that the polypharmacy rates differed by the type of coexisting chronic conditions; with the highest use among those with musculoskeletal conditions. This is not surprising because individuals with musculoskeletal conditions such as osteoarthritis use analgesic and NSAIDs to relieve the chronic pain. We also observed that patients with cluster of diseases (diabetes and cardiovascular diseases) have a higher rate of polypharmacy as compared with adults without the cluster of diseases which is consistent with the published literature. ${ }^{31}{ }^{35}$ Patients with diabetes and mental health conditions have also a high rate of polypharmacy as compared with those without mental health conditions. Further studies are required to explore the contributing factors, as there is no supporting evidence in the literature. Polypharmacy was also highly prevalent among patients with diabetes and respiratory diseases, which is consistent with data from previous studies, which showed higher rates of medication use in patients with COPD. ${ }^{36}$

Accordingly, healthcare providers need to routinely monitor these individuals for potentially inappropriate medications, adverse drug events and drug-drug interactions. For instance, in older individuals, comprehensive geriatric assessment has shown effective impact in decreasing the number of medications prescribed. ${ }^{37}$ Further, patients with diabetes and polypharmacy may benefit from multidisciplinary collaborative care model that involves pharmacist follow-up for the patients to assess the medication use and minimise polypharmacy. In an open-label, parallel-arm, randomised, controlled study, collaborative care has been associated with improvement in the management of diabetes and 
Table 3 AORs and 95\% Cls logistic regression on polypharmacy adults with diabetes, Electronic Health Records Database, 2016

AOR $\quad 95 \% \mathrm{Cl} \quad$ Significance

\begin{tabular}{|c|c|c|c|}
\hline \multicolumn{4}{|l|}{ Age group } \\
\hline $30-39$ vs $18-29$ & 1.48 & (1.00 to 2.18 ) & ** \\
\hline $40-49$ vs $18-29$ & 2.13 & (1.47 to 3.08 ) & *** \\
\hline $50-59$ vs $18-29$ & 3.54 & (2.46 to 5.11 ) & $* \star *$ \\
\hline $60-69$ vs $18-29$ & 5.11 & (3.51 to 7.44 ) & *** \\
\hline $70-79$ vs $18-29$ & 7.59 & (5.07 to 11.35 ) & 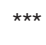 \\
\hline$\geq 80$ vs $18-29$ & 9.65 & (5.69 to 16.38 ) & *** \\
\hline
\end{tabular}

Marital status

\begin{tabular}{|c|c|c|c|}
\hline Single versus married & 1.16 & (0.96 to 1.40$)$ & \\
\hline \multicolumn{4}{|l|}{ Gender } \\
\hline Female versus male & 1.60 & (1.43 to 1.79$)$ & *** \\
\hline \multicolumn{4}{|l|}{ Nationality } \\
\hline Non-Saudi versus Saudi & 1.81 & (1.50 to 2.19$)$ & *** \\
\hline \multicolumn{4}{|l|}{ Cardiovascular conditions } \\
\hline Yes versus no & 2.89 & (2.54 to 3.29$)$ & *** \\
\hline \multicolumn{4}{|l|}{ Musculoskeletal conditions } \\
\hline Yes versus no & 3.16 & (2.31 to 4.30$)$ & *** \\
\hline \multicolumn{4}{|l|}{ Respiratory conditions } \\
\hline Yes versus no & 2.42 & (1.92 to 3.03$)$ & *** \\
\hline \multicolumn{4}{|l|}{ Mental health conditions } \\
\hline Yes versus no & 2.19 & (1.74 to 2.76$)$ & *** \\
\hline
\end{tabular}

Based on 8932 adults with diabetes, who visited outpatient's clinics from a tertiary hospital in 2016. Polypharmacy was defined as the cumulative use of five or more medications during the 1 -year period.

Asterisks $\left(^{*}\right)$ represent significant differences on polypharmacy compared with the reference group based on logistic regression. ${ }^{\star} \mathrm{P}<0.001,{ }^{* *} 0.001 \leq \mathrm{P}<0.01$.

AOR, adjusted OR.

reduction the healthcare cost. ${ }^{38}$ Pharmacists can help other healthcare providers in detecting polypharmacy, drug interactions and in providing recommendations for simplified medication regimens and minimising medications to positively impact health outcomes of diabetes care. $^{39} 40$

We also looked at other related factors for polypharmacy. We observed that women were more likely to have a polypharmacy compared with men, this is consistent with the findings from data among patients with diabetes. ${ }^{10}$ In addition, studies have reported that women in the general population have a higher use of prescribed and non-prescribed medications, and higher healthcare utilisation as compared with men. ${ }^{41-44}$ This could be because women tend to be more concerned about their health and seek health services more often than men. ${ }^{45}$ It has to be noted that the majority of patients with diabetes in our study were women, this is not surprising since the rate of diabetes is higher in women as compared with men in Saudi Arabia. ${ }^{2}$

\section{Strengths and limitations}

This study has some limitations; we defined polypharmacy as the cumulative use of five or more medications during a 1-year period rather than the concurrent use of medications, using this definition may have overestimated the rate of polypharmacy. We did not control for the severity of diabetes using the Diabetes Complications Severity Index, which may affect the rate of polypharmacy. We have also only observed filled prescriptions and not actual use of the medications. By using the EHR data, we cannot eliminate some risk of bias; inaccurate information or missing data related to the use of EHR. Due to the cross-sectional nature of the data, it is difficult to assess any causal relationships. People with the end-of-life care were included in the study, which may have also overestimated the rate of polypharmacy. ${ }^{46}$ Moreover, we have included all therapeutic medication classes, including OTC medications and vitamins in our definition, which may have overestimated the rate of polypharmacy. It has to be noticed that not all polypharmacy is harmful; however, we have not assessed if the polypharmacy was appropriate or not. This study was conducted in a tertiary hospital in Riyadh; therefore, the findings from this study cannot be generalised to primary care settings or to other regions in Saudi Arabia. In addition, we cannot exclude selection bias; patients included in this study may be sicker, have sever diabetes and higher rates of comorbidities as compared with individuals seen in primary care settings.

Despite these limitations, this study has many advantages such as the use of large sample size, which allowed us to identify the prevalence of polypharmacy among a subgroup of patients. Furthermore, findings from this study added to the existing literature on the prevalence of polypharmacy among all age groups and identified the individuals who have a high risk of polypharmacy based on their comorbidities. In addition, our results highlighted the need for routine monitoring of highrisk individuals for drug-related problems. Therefore, future studies are required to identify the rate of polypharmacy among other healthcare settings and assess the impact of pharmacist-led interventions on the rate of polypharmacy in patients with diabetes.

\section{CONCLUSION}

Polypharmacy is very common among adults with diabetes; particularly among individuals with multiple chronic conditions. Older adults patients have a higher rate of polypharmacy, which could be due to the increased number of multiple chronic conditions in this population. Moreover, patients with coexisting cardiovascular, mental and musculoskeletal chronic conditions are at a high risk of polypharmacy. Individuals with diabetes may benefit from simplified treatment regimens; thereby enhancing the health outcomes of this population. 


\section{Ethics and data confidentiality}

Confidentiality of the data was maintained throughout the research process. Retrieved data were stored and saved as coded excel files. A customised formula was used to generate the study-encrypted identification assigned to each participant and replaced patients' medical record number. Data extracted were stored at the research unit at the tertiary hospital on secured, password-protected and limited accessed computers.

Acknowledgements The project was fully supported financially by the Vice Deanship of Research Chairs, King Saud University Riyadh, Saudi Arabia.

Contributors MA, BB, TMA, HA, NA, RA, HD and US participated in designing the study, drafting the manuscript, analysis, interpretation of the findings, revising the manuscript content and gave final approval of the final version of this manuscript.

Funding This research received no specific grant from any funding agency in the public, commercial or not-for-profit sectors.

Competing interests None declared.

Patient consent Obtained.

Ethics approval Institutional Review Board (IRB) at King Saud University Medical City approval was obtained to conduct the study (IRB number: E-17-2601).

Provenance and peer review Not commissioned; externally peer reviewed.

Data sharing statement № additional data are available.

Open Access This is an Open Access article distributed in accordance with the Creative Commons Attribution Non Commercial (CC BY-NC 4.0) license, which permits others to distribute, remix, adapt, build upon this work non-commercially, and license their derivative works on different terms, provided the original work is properly cited and the use is non-commercial. See: http://creativecommons.org/ licenses/by-nc/4.0/

(C) Article author(s) (or their employer(s) unless otherwise stated in the text of the article) 2018. All rights reserved. No commercial use is permitted unless otherwise expressly granted.

\section{REFERENCES}

1. Al-Nozha MM, Al-Maatouq MA, Al-Mazrou YY, et al. Diabetes mellitus in Saudi Arabia. Saudi Med J 2004;25:1603-10.

2. Alqurashi KA, Aljabri KS, Bokhari SA. Prevalence of diabetes mellitus in a Saudi community. Ann Saudi Med 2011;31:19-23.

3. Guariguata L, Whiting DR, Hambleton I, et al. Global estimates of diabetes prevalence for 2013 and projections for 2035. Diabetes Res Clin Pract 2014;103:137-49.

4. Lozano R, Naghavi M, Foreman K, et al. Global and regional mortality from 235 causes of death for 20 age groups in 1990 and 2010: a systematic analysis for the Global Burden of Disease Study 2010. Lancet 2012;380:2095-128.

5. Teljeur C, Smith SM, Paul G, et al. Multimorbidity in a cohort of patients with type 2 diabetes. Eur J Gen Pract 2013;19:17-22.

6. Good CB. Polypharmacy in elderly patients with diabetes. Diabetes Spectrum 2002;15:240-8.

7. Austin RP. Polypharmacy as a risk factor in the treatment of type 2 diabetes. Diabetes Spectrum 2006;19:13-16.

8. Gadsby R, Galloway M, Barker P, et al. Prescribed medicines for elderly frail people with diabetes resident in nursing homes-issues of polypharmacy and medication costs. Diabet Med 2012;29:136-9.

9. Grant RW, Devita NG, Singer DE, et al. Polypharmacy and medication adherence in patients with type 2 diabetes. Diabetes Care 2003;26:1408-12.

10. Noale M, Veronese N, Cavallo Perin P, et al. Polypharmacy in elderly patients with type 2 diabetes receiving oral antidiabetic treatment. Acta Diabetol 2016;53:323-30.

11. Salih SB, Yousuf M, Durihim H, et al. Prevalence and associated factors of polypharmacy among adult Saudi medical outpatients at a tertiary care center. J Family Community Med 2013;20:162.

12. Nguyen JK, Fouts MM, Kotabe SE, et al. Polypharmacy as a risk factor for adverse drug reactions in geriatric nursing home residents. Am J Geriatr Pharmacother 2006;4:36-41.
13. Viktil KK, Blix HS, Moger TA, et al. Polypharmacy as commonly defined is an indicator of limited value in the assessment of drugrelated problems. Br J Clin Pharmacol 2007;63:187-95.

14. Rodrigues MCS, Oliveira Cde. Drug-drug interactions and adverse drug reactions in polypharmacy among older adults: an integrative review. Rev Lat Am Enfermagem 2016;24.

15. Golchin N, Frank SH, Vince A, et al. Polypharmacy in the elderly. $J$ Res Pharm Pract 2015;4:85.

16. Bailey CJ, Kodack M. Patient adherence to medication requirements for therapy of type 2 diabetes. Int J Clin Pract 2011;65:314-22.

17. Willey CJ, Andrade SE, Cohen J, et al. Polypharmacy with oral antidiabetic agents: an indicator of poor glycemic control. Am J Manag Care 2006;12:435.

18. Peron EP, Ogbonna KC, Donohoe KL. Antidiabetic medications and polypharmacy. Clin Geriatr Med 2015;31:17-27.

19. Breuker C, Abraham O, di Trapanie L, et al. Patients with diabetes are at high risk of serious medication errors at hospital: Interest of clinical pharmacist intervention to improve healthcare. Eur J Intern Med 2017;38:38-45

20. Rollason V, Vogt N. Reduction of polypharmacy in the elderly. Drugs Aging 2003;20:817-32.

21. Huang ES, Karter AJ, Danielson KK, et al. The association between the number of prescription medications and incident falls in a multiethnic population of adult type-2 diabetes patients: the diabetes and aging study. J Gen Intern Med 2010;25:141-6.

22. Shah BM, Hajjar ER. Polypharmacy, adverse drug reactions, and geriatric syndromes. Clin Geriatr Med 2012;28:173-86.

23. Maher RL, Hanlon J, Haijar ER. Clinical consequences of polypharmacy in elderly. Expert Opin Drug Saf 2014;13:57-65.

24. Santibáñez-Beltrán S, Villarreal-Ríos E, Galicia-Rodríguez L, et al. [Economic cost of polypharmacy in the elderly in primary health care]. Rev Med Inst Mex Seguro Soc 2013;51:192-9.

25. Slabaugh SL, Maio V, Templin M, et al. Prevalence and risk of polypharmacy among the elderly in an outpatient setting. Drugs Aging 2010;27:1019-28.

26. Wright EE, Stonehouse AH, Cuddihy RM. In support of an early polypharmacy approach to the treatment of type 2 diabetes. Diabetes Obes Metab 2010;12:929-40.

27. Bauer S, Nauck MA. Polypharmacy in people with Type 1 and Type 2 diabetes is justified by current guidelines--a comprehensive assessment of drug prescriptions in patients needing inpatient treatment for diabetes-associated problems. Diabet Med 2014;31:1078-85.

28. Monégat M, Sermet C, Perronnin M, et al. Polypharmacy: Definitions, measurement and stakes involved. Review of the literature and measurement tests. Quest d'économie la santé 2014;204:1-8.

29. Grimmsmann T, Himmel W. Polypharmacy in primary care practices: an analysis using a large health insurance database. Pharmacoepidemiol Drug Saf 2009;18:1206-13.

30. Iglay K, Hannachi H, Joseph Howie P, et al. Prevalence and coprevalence of comorbidities among patients with type 2 diabetes mellitus. Curr Med Res Opin 2016;32:1243-52.

31. Vyas A, Pan X, Sambamoorthi U. Chronic condition clusters and polypharmacy among adults. Int J Family Med 2012;2012:1-8.

32. Balkhi B, AlQahtani N, Alwhaibi M, et al. Prevalence and factors associated with polypharmacy use among adult patients in Saudi Arabia. J Patient Saf 2017:1.

33. Lewis NJ, Bugdalski-Stutrud C, Abate MA, et al. The medication assessment program: Comprehensive medication assessments for persons taking multiple medications for chronic diseases. J Am Pharm Assoc 2008;48:171-80.

34. Feng X, Tan X, Riley B, et al. Polypharmacy and multimorbidity among medicaid enrollees: A multistate analysis. Popul Health Manag 2018;21:123-9.

35. Nobili A, Marengoni A, Tettamanti M, et al. Association between clusters of diseases and polypharmacy in hospitalized elderly patients: results from the REPOSI study. Eur J Intern Med 2011;22:597-602.

36. Franssen FM, Spruit MA, Wouters EF. Determinants of polypharmacy and compliance with GOLD guidelines in patients with chronic obstructive pulmonary disease. Int J Chron Obstruct Pulmon Dis 2011;6:493.

37. Sergi G, De Rui M, Sarti S, et al. Polypharmacy in the elderly. Drugs Aging 2011;28:509-19.

38. Siaw M. Collaborative care cost saving in Asian patients with T2DM. PharmacoEconomics \& Outcomes News 2017;779:10-13.

39. Chumney EC, Robinson LC. The effects of pharmacist interventions on patients with polypharmacy. Pharm Pract 2006;4:103-9.

40. Wang Y, Yeo QQ, Ko Y. Economic evaluations of pharmacistmanaged services in people with diabetes mellitus: a systematic review. Diabet Med 2016;33:421-7. 
41. Qato DM, Alexander GC, Conti RM, et al. Use of prescription and over-the-counter medications and dietary supplements among older adults in the United States. JAMA 2008;300:2867-78.

42. Bertakis KD, Azari R, Helms LJ, et al. Gender differences in the utilization of health care services. J Fam Pract 2000;49:147.

43. Redondo-Sendino A, Guallar-Castillón P, Banegas JR, et al. Gender differences in the utilization of health-care services among the older adult population of Spain. BMC Public Health 2006;6:155.
44. Loikas D, Wettermark B, von Euler M, et al. Differences in drug utilisation between men and women: a cross-sectional analysis of all dispensed drugs in Sweden. BMJ Open 2013;3:e002378.

45. Venturini CD, Engroff P, Ely LS, et al. Gender differences, polypharmacy, and potential pharmacological interactions in the elderly. Clinics 2011;66:1867-72.

46. Maddison AR, Fisher J, Johnston G. Preventive medication use among persons with limited life expectancy. Prog Palliat Care 2011;19:15-21. 